\title{
E-Commerce Adoption as a Predictor of the Perceived Strategic Value of E-Commerce among E-Commerce Adopter SMEs in Turkey
}

\author{
Kadri Gokhan Yilmaz \\ Business Administration, Gazi University \\ Turkey \\ kgyilmaz@gazi.edu.tr \\ Ali Ayci \\ Institutional Training Director KOSGEB \\ Turkey \\ ali.ayci@kosgeb.gov.tr
}

\author{
Aybegum Gungordu \\ Business Administration, Gazi University \\ Turkey \\ aybegum.gungordu@gmail.com \\ Tuba Yumusak \\ Business Administration, Gazi University \\ Turkey \\ t_tokucoglu@hotmail.com
}

\begin{abstract}
The purpose of this study is to explore the relationship between the perceived strategic value of ecommerce and e-commerce adoption among e-commerce adopter SMEs in Turkey. We used reliability and validity analyses, exploratory and confirmatory factor analyses and multiple regression analyses. Our sample consists of 577 SMEs in Turkey. We found that perceived strategic value of IT has two dimensions such as organizational support and managerial decision aids. Furthermore, e-commerce adoption has three dimensions such as perceived usefulness, organizational factors and external pressure; we found that organizational support has a positive and significant effect on organizational factors and perceived usefulness. Managerial decision aids has a positive and significant effect on external pressure, perceived usefulness and organizational factors.
\end{abstract}

Keywords: e-commerce adoption, SME, Perceived strategic value of e-commerce, Turkey.

\section{INTRODUCTION}

Turkey as an emerging country has more than 260000 SMEs. SMEs are identified mainly according to their number of employees. The enterprises or the economic units which have the number of employees less than 250 and annual turnover or any of their balance sheets does not exceed 40 million Turkish liras are determined as SMEs. SMEs are classified as micro, small and medium enterprises. The definition criteria of the SMEs in Turkey are shown in Table 1.

Table1. The Definition of National SMEs

\begin{tabular}{|c|c|c|c|c|c|}
\hline Scale & Number of Employees & \multirow{4}{*}{ and } & Annual Turnover & \multirow{4}{*}{ or } & Balance Sheet \\
\hline Micro & $<10$ & & $\leq 1$ million & & $\leq 1$ million \\
\hline Small & $10-49$ & & $\leq 8$ million & & $\leq 8$ million \\
\hline Medium & $50-249$ & & $\leq 40$ million & & $\leq 40$ million \\
\hline
\end{tabular}

Source: SME Strategy and Action Plan (2015-2018).

The definition of SMEs by EU can be seen in Table 2. While the number of employees is similar, columns of annual turnover and balance sheet are different than Turkey.

Table2. The Definition of SMEs by EU

\begin{tabular}{|c|c|c|c|c|c|}
\hline Scale & Number of Employees & \multirow{4}{*}{ and } & Annual Turnover & \multirow{4}{*}{ or } & Balance Sheet \\
\hline Micro & $<10$ & & $\leq € 2$ million & & $\leq € 2$ million \\
\hline Small & $10-49$ & & $\leq € 10$ million & & $\leq € 10$ million \\
\hline Medium & $50-249$ & & $\leq € 50$ million & & $\leq € 50$ million \\
\hline
\end{tabular}

Source: SME Strategy and Action Plan (2015-2018).

Due to their numerical quantity and as well as the significant contribution to the economy, almost every nation has a policy about the SMEs in order to fulfill their emergence, growth and survival. 
Within the scope of this policy, countries offer support and services to SMEs and take appropriate actions that improve their competitiveness in the economy. SMEs are also engaged in e-commerce. Grandon and Pearson (2004) define e-commerce in a B2C context: "the process of buying and selling products or services using electronic data transmission via the Internet and www." In the literature (Nasco et al., 2007; Pavlou and Fygenson, 2006), Ajzen (1991)'s Theory of Planned Behaviour was mainly used for predicting e-commerce adoption. Furthermore, Technology Acceptance Model is utilized in some studies such as Grandon and Pearson (2004)'s and El-Gohary (2012)'s study and resource-based-view of a firm is used in Ramanathan et al. (2012)'s study.

Thus, the purpose of this study is to explore the relationship between the perception of strategic value and e-commerce adoption on SMEs in Turkey. Therefore, we seek answers for questions such as:

1) Which dimensions does the perception of strategic value have for SMEs in Turkey?

2) Which factors influence e-commerce adoption for SMEs in Turkey?

3) Is there a relationship between perception of strategic value and e-commerce adoption?

\section{LiteratURE REVIEW}

\section{A. Perceived Strategic Value of Information Technologies}

Grandon and Pearson (2004) found that perception of strategic value consists of three dimensions which are organizational support, managerial productivity and strategic decision aids. Authors were inspired from Subramanian and Nosek (2001)'study in which perceived strategic value is measured with three dimensions such as operational support, managerial productivity and strategic decision aids. Kwun et al. (2009) found that perception of perceived strategic value of e-commerce was influenced by organization compatibility, entrepreneurial mindset and industry competitiveness.

\section{B. E-Commerce Adoption}

E-commerce adoption is explored in the literature by both from the perspective of SMEs (Chong and Bauer, 2000; Grandon and Pearson, 2004; Nasco et. al, 2007; MacGregor and Vrazalic, 2008; Alam et al., 2011; El-Gohary, 2012; Ramanathan et al., 2012; Zaied, 2012; Lim et.al, 2013) and consumers (Pavlou and Fygenson, 2006).

Chong and Bauer (2000) identified the factors affecting the adoption of commerce as internal environmental factors (organizational, technological and communication factors) and external environmental factors (national and industry factors). Grandon and Pearson (2004) found that factors influencing adoption of e-commerce are organizational readiness, external pressure, perceived ease of use and perceived usefulness. Nasco et al. (2007) found that the subjective norm and attitude constructed positively and significantly to predict intentions; however, the perceived behavioral control construct did not according to hierarchical regression results of 212 SMEs. MacGregor and Vrazalic (2008) highlighted regarding e-commerce adoption, his comparison of organizational barriers and technical barriers revealed the former to be uppermost in the minds of owner/managers. Thus, the results pointed out that the owner/manager and the market focus of the business to be the main barriers concerning e-commerce adoption. Alam et al. (2011) indicated that relative advantage, compatibility, organizational readiness, manager's characteristics, and security are the factors significantly influencing e-commerce adoption. Ramanathan et al. (2012) found that operations and marketing aspects of e-commerce to have significant influence on performance of SMEs. The comparison between the size of SMEs - measured in number of employees - and the e-commerce experience - measured by the length of time SMEs have adopted e-commerce experience - pointed to the former to moderate the influence of operations and marketing aspects on performance, whereas the latter not. El-Gohary (2012) found that both the internal and external factors to have great influence on the adoption of e-marketing by Egyptian tourism organizations which can be seen in the e-commerce context. Zaied (2012) found that regarding their importance, technical barriers, legal and regulatory barriers, political barriers, and social and culture barriers are the barriers along ecommerce adoption, respectively. The lack of Internet security is referred to be the highest problem to hinder e-commerce practices in SMEs in Egypt by all respondents. 80\% of respondents pointed to following barriers to be the most important barriers: limited use of Internet banking and web portals by SMEs; cost being too high; changes in government policy and lack of e-commerce standards. Other barriers such as challenges in changing the existing working procedures; and lack of external pressure from suppliers and customers were not indicated as important. Lim et al. (2013) found the 
critical elements required for e-commerce adoption as a result of the preliminary interviews. Authors also stated that critical factors affecting SMEs to adopt e-Commerce are organizations, consumers and the government.

As for the consumers' point of view, Pavlou and Fygenson (2006) examined the process of getting information and purchasing a product from a Web vendor. Authors found that trust and technology adoption variables (perceived usefulness and ease of use) were salient beliefs for predicting ecommerce adoption.

Therefore, in the present study, we propose,

H1: There is a significant relationship between the dimensions of perceived strategic value of ecommerce and dimensions of e-commerce adoption.

\section{METHOD}

In the current study, we used online survey method. We used Grandon and Pearson (2004)'s perceived strategic value of e-commerce scale and e-commerce adoption scale. Surveys were send out to 50.000 SMEs in overall Turkey and only 2681 of them returned. Among them, 577 surveys were found usable. Top executives or owners of SMEs filled out the surveys. Scales were measured on a 7 point Likert scale ( $1=$ strongly agree, $7=$ strongly disagree $)$.

As for the perceived strategic value of e-commerce scale, questions started with the sentence: "In order to provide strategic value to the organization, electronic commerce should help......" and SMEs' perceptions of strategic value of electronic commerce is measured. Moreover, for the ecommerce adoption scale, SMEs' perceptions of adopting electronic commerce are measured.

Both of the questionnaires were in English and translated into Turkish, then back translated into English as McGorry (2000) suggested. We pretested the questionnaires on 100 SMEs before conducting the surveys. We tested reliability issues for the pilot study and found that both scales are extremely reliable according to Hair et al. (1998) who suggest that the Cronbach Alpha Coefficient has to be at least 0.60 for being satisfactory. For the perception of strategic value scale, Cronbach Alpha Coefficient is 0.963 and for the e-commerce adoption scale, Cronbach Alpha Coefficient is 0.959. We have to note that missing values in the dataset are replaced with mean values. Descriptive statistics for our sample is shown in Table 3.

Table3. Descriptive Statistics

\begin{tabular}{|l|l|l|l|l|l|}
\hline Number of employees & Frequency & $\%$ & Industry & Frequency & $\%$ \\
\hline $0-9$ & 504 & 87,3 & Production & 324 & 56,2 \\
\hline $10-49$ & 9 & 1,6 & Information & 56 & 9,7 \\
\hline $50-249$ & 64 & 11,1 & Service & 49 & 8,5 \\
\hline Internet service provider in place & Frequency & $\%$ & E-commerce & 12 & 2,1 \\
\hline Yes & 577 & 100 & Retailing & 47 & 8,1 \\
\hline No & 0 & 0 & Wholesaling & 56 & 9,7 \\
\hline Organization has web site & Frequency & $\%$ & Health & 33 & 5,7 \\
\hline Yes & 524 & 90,8 & $\begin{array}{l}\text { Foundation year } \\
\text { of the company }\end{array}$ & Frequency & $\%$ \\
\hline No & & 93 & Before 2000 & 183 & 31,7 \\
\hline Electronic commerce already in place & Frequency & $\%$ & After 2000 & 385 & 66,7 \\
\hline Yes & 577 & 100 & Did not specify & 9 & 0,15 \\
\hline No & 0 & 0 & & & \\
\hline
\end{tabular}

\section{FINDINGS}

After the pilot study, we began our main study by performing EFA analyses for both scales. Regarding EFA analysis, our extraction method is Principal Component Analysis and our rotation method is Varimax with Kaiser Normalization. Eigenvalues above 1.0 were considered in the analyses. Only factor loadings of 0.50 or above are reported for EFA and CFA as suggested by Hair et al. (1998) as a cut-off value for discriminant and convergent validity. Results of the exploratory factor analyses for both scales can be seen in Table 4 and Table 5 . 
Kadri Gokhan Yilmaz et al.

Table4. Rotated Component Matrix of Perceived Strategic Value of E-Commerce Scale

\begin{tabular}{|l|l|l|}
\hline \multirow{2}{*}{ Question no } & Factor & Factor Loadings \\
\cline { 2 - 3 } & Organizational support (7 items) & \\
\hline PSV3 & Improve distribution channels & .815 \\
\hline PSV2 & Improve customer services & .795 \\
\hline PSV1 & Reduce costs of business operations & .793 \\
\hline PSV4 & Reap operational benefits & .762 \\
\hline PSV6 & Support linkages with suppliers & .760 \\
\hline PSV7 & Increase ability to compete & .729 \\
\hline PSV5 & Provide effective support role to operations & .724 \\
\hline & Managerial decision aids (6 items) & .754 \\
\hline PSV11 & improve productivity of managers & .748 \\
\hline PSV12 & Support strategic decisions of managers & .743 \\
\hline PSV10 & Improve communication in the organization & .708 \\
\hline PSV9 & $\begin{array}{l}\text { Provide managers access to methods and models in making } \\
\text { functional area decisions }\end{array}$ & .705 \\
\hline PSV14 & Support cooperative partnerships in the industry & .674 \\
\hline PSV15 & Provide information for strategic decision & \\
\hline
\end{tabular}

Total variance explained: $72.380 \%$, KMO: 0.952, Bartlett's test of Sphericity: $X^{2}=8404.115, d f=105, p<0.05$

PSV8 and PSV13 are excluded from the EFA analysis; because they had more than one factor loadings and the difference between these loadings was lower than 0.10 . Factor loadings are in the range of 67 percent and 81 percent.

Grandon and Pearson (2004) found that items between PSV1 and PSV7 form the dimension named "organizational support" which is similar with our findings. Thus, our first dimension is "organizational support". Whereas the other dimensions named "managerial productivity" has items between PSV8-PSV11 and "decision aids" has items between PSV12-PSV15 have merged into another dimension according to the findings of our study. We named this combined dimension as "managerial decision aids".

Table5. Rotated Component Matrix of E-Commerce Adoption Scale

\begin{tabular}{|c|c|c|}
\hline \multirow[t]{2}{*}{ Question no } & Factor & Factor Loadings \\
\hline & \multicolumn{2}{|l|}{ Perceived usefulness (10 items) } \\
\hline EA19 & $\begin{array}{l}\text { Using electronic commerce would improve } \\
\text { my job performance }\end{array}$ & .892 \\
\hline EA21 & $\begin{array}{l}\text { Using electronic commerce would enhance } \\
\text { my effectiveness on the job }\end{array}$ & .884 \\
\hline EA18 & $\begin{array}{l}\text { Using electronic commerce would enable } \\
\text { my company to accomplish specific tasks } \\
\text { more quickly }\end{array}$ & .874 \\
\hline EA20 & $\begin{array}{l}\text { Using electronic commerce in my job } \\
\text { would increase my productivity }\end{array}$ & .865 \\
\hline EA17 & I would find electronic commerce easy to use & .858 \\
\hline EA22 & $\begin{array}{l}\text { Using electronic commerce would make } \\
\text { it easier to do my job }\end{array}$ & .845 \\
\hline EA15 & $\begin{array}{l}\text { My interaction with electronic commerce } \\
\text { would be clear and understandable }\end{array}$ & .776 \\
\hline EA13 & $\begin{array}{l}\text { Learning to operate electronic commerce } \\
\text { would be easy for me }\end{array}$ & .703 \\
\hline EA16 & $\begin{array}{l}\text { It would be easy for me to become skillful at } \\
\text { using electronic commerce }\end{array}$ & .689 \\
\hline \multirow[t]{2}{*}{ EA14 } & $\begin{array}{l}\text { I would find electronic commerce to be } \\
\text { flexible to interact with }\end{array}$ & .687 \\
\hline & \multicolumn{2}{|l|}{ Organizational factors (7 items) } \\
\hline EA4 & $\begin{array}{l}\text { Our organization perceives that electronic } \\
\text { commerce is consistent with values }\end{array}$ & .808 \\
\hline EA3 & $\begin{array}{l}\text { Our organization perceives that electronic } \\
\text { commerce is consistent with culture }\end{array}$ & .807 \\
\hline EA2 & $\begin{array}{l}\text { Our organization has the technological } \\
\text { resources to adopt electronic commerce }\end{array}$ & .804 \\
\hline
\end{tabular}


E-Commerce Adoption as a Predictor of the Perceived Strategic Value of E-Commerce among E-Commerce Adopter SMEs in Turkey

\begin{tabular}{|c|l|c|}
\hline \hline EA5 & $\begin{array}{l}\text { Our organization perceives that electronic } \\
\text { commerce is consistent with preferred work practices }\end{array}$ & .786 \\
\hline EA1 & $\begin{array}{l}\text { Our organization has the financial resources } \\
\text { to adopt electronic commerce }\end{array}$ & .732 \\
\hline EA6 & $\begin{array}{l}\text { Electronic commerce would be consistent with } \\
\text { our existing technology infrastructure }\end{array}$ & .640 \\
\hline EA8 & $\begin{array}{l}\text { Competition is a factor in our decision to adopt } \\
\text { electronic commerce }\end{array}$ & .528 \\
\hline EA10 & $\begin{array}{l}\text { We depend on other firms that are already } \\
\text { using electronic commerce }\end{array}$ & .852 \\
\hline EA11 & $\begin{array}{l}\text { Our industry is pressuring us to adopt } \\
\text { electronic commerce }\end{array}$ & $\begin{array}{l}\text { Social factors are important in our decision to } \\
\text { adopt electronic commerce }\end{array}$ \\
\hline EA9 & S & .787 \\
\hline
\end{tabular}

Total variance explained $=73.417 \%, K M O=0.960$, Bartlett's test of Sphericity: $X^{2}=14528.47 ; d f=253, p<0.05$

EA23 is excluded according to the EFA results as a reason of it has a factor loading under 0.50 . EA12 and EA7 are excluded because they had more than one factor loadings and the difference between these loadings were lower than 0.10 . Factor loadings are in the range of 52 percent and 89 percent.

Grandon and Pearson (2004) found that items EA1 and EA2 form the dimension named "organizational readiness". They also found that items between EA3 and EA5 form the dimension named "compatibility". According to our findings, these two dimensions merged into another dimension which we named it as "organizational factors". Furthermore, Grandon and Pearson (2004) found that items between EA8 and EA12 constitute the dimension named "external pressure" which is similar to our findings. This is why we named our other dimension as "external pressure." Grandon and Pearson (2004) also found that items between EA13 and EA17 are named as "ease of use" and items between EA18 and EA23 are named as "perceived usefulness". In our study, these two dimensions merged and we named this combined dimension as "perceived usefulness".

After exploratory factor analyses, we performed first-order confirmatory factor analyses for both scales. First-order CFA analysis results of e-commerce adoption can be seen in Table 6 .

Table6. First-Order CFA Analysis Results of E-Commerce Adoption

\begin{tabular}{|l|l|l|l|c|c|}
\hline \multicolumn{2}{|l|}{ Path } & \multicolumn{2}{c|}{ Standardized factor loadings } & SE & t \\
\hline EA1 & $<---$ & OF & .651 & .040 & 18.190 \\
\hline EA2 & $<---$ & OF & .909 & .032 & 32.865 \\
\hline EA3 & $<---$ & OF & .931 & .032 & 34.506 \\
\hline EA4 & $<---$ & OF & .888 & & \\
\hline EA9 & $<---$ & EP & .717 & .050 & 16.654 \\
\hline EA10 & $<---$ & EP & .880 & & \\
\hline EA11 & $<---$ & EP & .728 & .050 & 16.856 \\
\hline EA15 & $<---$ & PUS & .889 & .025 & 35.366 \\
\hline EA16 & $<---$ & PUS & .872 & .033 & 27.457 \\
\hline EA17 & $<---$ & PUS & .922 & .024 & 39.481 \\
\hline EA19 & $<---$ & PUS & .926 & & .027 \\
\hline EA22 & $<---$ & PUS & .887 & .029 & 30.625 \\
\hline EA14 & $<---$ & PUS & .840 & & 35.239 \\
\hline
\end{tabular}

CMIN/DF: 4.936; RMSEA: 0.083; GFI: 0.924; CFI: 0.964; IFI: 0.965

EP: External pressure, OF: Organizational factors, PUS: Perceived usefulness.

As for the E-commerce adoption, errors associated with items EA16 and EA19 were allowed to correlate. As can be seen in table 7, factor loadings are in the range of 65 percent and 93 percent. 
Kadri Gokhan Yilmaz et al.

Table7. First-Order CFA Analysis Results of Perceived Strategic Value of E-Commerce Scale

\begin{tabular}{|c|c|c|c|c|c|}
\hline \multicolumn{3}{|l|}{ Path } & \multirow{2}{*}{$\begin{array}{l}\text { Standardized factor loadings } \\
.700\end{array}$} & \multirow{2}{*}{$\begin{array}{c}\text { SE } \\
.049\end{array}$} & \multirow{2}{*}{$\begin{array}{l}\mathbf{t} \\
19.102\end{array}$} \\
\hline PSV1 & $<---$ & OS & & & \\
\hline PSV2 & $<---$ & OS & .814 & .030 & 32.674 \\
\hline PSV3 & $<---$ & OS & .837 & & \\
\hline PSV4 & $<---$ & OS & .862 & .040 & 26.123 \\
\hline PSV5 & $<--$ & OS & .823 & .044 & 24.231 \\
\hline PSV6 & $<--$ & OS & .821 & .041 & 24.152 \\
\hline PSV7 & $<---$ & OS & .872 & .041 & 26.641 \\
\hline PSV9 & $<---$ & $\mathrm{MD}$ & .773 & .040 & 23.483 \\
\hline PSV10 & $<---$ & $\mathrm{MD}$ & .924 & .032 & 33.080 \\
\hline PSV11 & $<---$ & MD & .880 & & \\
\hline PSV12 & $<---$ & MD & .867 & .022 & 43.501 \\
\hline PSV14 & $<---$ & $\mathrm{MD}$ & .853 & .034 & 28.090 \\
\hline PSV15 & $<---$ & MD & .500 & .048 & 11.620 \\
\hline
\end{tabular}

CMIN/DF: 4.903; RMSEA: 0.082; GFI: 0.926; CFI: 0.965; IFI: 0.965

OS: Organizational support, MD: Managerial decision aids.

As for the E-commerce adoption, errors associated with items PSV2 and PSV3; and items PSV11 and PSV12 were allowed to correlate. As can be seen in table 5, factor loadings are in the range of 50 percent and 92 percent.

Suggested standards for fit indexes are such as CMIN/DF has to be below and equal to 5 (Marsh and Hocevar, 1985). RMSEA which is below and equal to 0.08 is found acceptable and if it is between and equal to 0.08 and 0.10, it is found mediocre (Maccallum et al., 2001; Byrne, 2010). GFI, CFI and IFI which are above and equal to 0.90 are found acceptable (Bollen, 1989; Bentler, 1992; Engel et al., 2003). As can be seen in table 6 and Table 7, fit indexes for both scales are acceptable. Furthermore, we carried out Pearson correlation analysis, validity analysis and reliability analysis which are showed in Table 8.

Table8. Pearson Correlation Results, CR, AVE and Cronbach Alpha Coefficients

\begin{tabular}{|l|l|l|l|l|l|l|l|l|l|l|}
\hline & Mean & $\begin{array}{c}\text { Std. } \\
\text { Deviation }\end{array}$ & OS & MD & OF & EP & PUS & AVE & CR & $\begin{array}{c}\text { Cronbach } \\
\text { Alpha }\end{array}$ \\
\hline OS & 5.2342 & 1.12387 & 1 & & & & & 0.67 & 0.94 & 0.935 \\
\hline MD & 4.9555 & 1.12866 & $.790^{* *}$ & 1 & & & & 0.65 & 0.91 & 0.909 \\
\hline OF & 4.9016 & 1.21557 & $.551^{* *}$ & $.636^{* *}$ & 1 & & & 0.72 & 0.91 & 0.907 \\
\hline EP & 3.7741 & 1.40422 & $.262^{* *}$ & $.388^{* *}$ & $.392^{* *}$ & 1 & & 0.60 & 0.82 & 0.816 \\
\hline PUS & 5.1464 & 1.19152 & $.705^{* *}$ & $.693^{* *}$ & $.719^{* * *}$ & $.385^{* *}$ & 1 & 0.79 & 0.95 & 0.956 \\
\hline
\end{tabular}

$* * p<0.01$

OS: Organizational support, MD: Managerial decision aids, OF: Organizational factors, EP: External pressure, PUS: Perceived usefulness. AVE: Average variance extracted. CR: Composite reliability.

According to Table 6, all of the correlations among variables are below 0.80 . Cronbach Alpha coefficients show that the both scales are reliable. To test construct validity, we calculated composite reliability for all dimensions and these are reliable as they are above 0.70 suggested by Nunnally and Bernstein (1994). As for convergent validity, AVE values are above 0.50 (Hair et al., 1998; Bagozzi and Yi, 1988). For discriminant validity, square root of each variable's AVE value is greater than the correlation of each dimension with other dimensions (Fornel and Larcker, 1981).

Lastly, we performed multiple regression analyses to test the relationships between dependent variables (organizational factors, external pressure and perceived usefulness) and independent variables (managerial decision aids and organizational support) that can be seen in Table 9 and Table 10. For all of the multiple regressions, the biggest VIF value is below 10, tolerance values are greater than 0.20 and condition indices are below 30. Thus, we can say that multicollinearity does not exist between variables according to our findings. 
E-Commerce Adoption as a Predictor of the Perceived Strategic Value of E-Commerce among E-Commerce Adopter SMEs in Turkey

Table9. Multiple Regression Results I

\begin{tabular}{|c|c|c|c|c|c|c|c|}
\hline & \multicolumn{2}{|c|}{$\begin{array}{l}\text { Unstandardized } \\
\text { Coefficients }\end{array}$} & \multirow{2}{*}{$\begin{array}{l}\text { Standardized } \\
\text { Coefficients } \\
\text { Beta }\end{array}$} & \multirow[b]{2}{*}{$\mathrm{t}$} & \multirow[b]{2}{*}{ Sig. } & \multicolumn{2}{|c|}{ Correlations } \\
\hline & $\mathrm{B}$ & Std. Error & & & & Zero-order & Partial \\
\hline Constant & 1.321 & 0.191 & - & 6.918 & 0.000 & - & - \\
\hline $\mathrm{OS}$ & 0.141 & 0.057 & 0.130 & 2.492 & 0.013 & 0.551 & 0.103 \\
\hline $\mathrm{MD}$ & 0.574 & 0.056 & 0.533 & 10.184 & 0.000 & 0.636 & 0.391 \\
\hline
\end{tabular}

$R=0.641, R^{2}=0.41, F_{(2,574)}=199.721, p=0.000$

Dependent Variable: OF: Organizational factors; Predictors: MD: Managerial decision aids, OS: Organizational support.

There is a significant relationship between "organizational factors" and all of the independent variables together as can be seen in Table $9\left(\mathrm{R}=0.641, \mathrm{R}^{2}=0.41, \mathrm{~F}_{(2,574)}=199.721, \mathrm{p}<0.01\right)$. All of the independent variables together explain approximately 41 percent of change in the total variance of organizational factors.

According to standardized regression coefficients, order of relative importance of predictor variables on organizational factors is managerial decisions aids and organizational support. When the t-test results which show the significance of regression coefficients are examined, it seems that managerial decision aids and organizational support are significant predictors on organizational factors.

When correlations are examined it seems that there is a correlation between organizational factors and organizational support ( $\mathrm{r}=0.551$; when other predictor is controlled $\mathrm{r}=0.103)$ and managerial decision aids $(\mathrm{r}=0.636$; when other predictor is controlled $\mathrm{r}=0.391)$.

Based upon multiple regression results, the equation can be written as follows:

Organizational factors $=1.321+0.574$ Managerial decision aids+0.141Organizational support

Table10. Multiple Regression Results II

\begin{tabular}{|l|l|l|l|l|l|l|l|}
\hline & \multicolumn{2}{|l|}{$\begin{array}{l}\text { Unstandardized } \\
\text { Coefficients }\end{array}$} & $\begin{array}{l}\text { Standardized } \\
\text { Coefficients }\end{array}$ & & & \multicolumn{2}{l|}{ Correlations } \\
\hline & B & Std. Error & Beta & t & Sig. & Zero-order & Partial \\
\hline Constant & 1.578 & 0.264 & - & 5.978 & 0.000 & - & - \\
\hline OS & -0.149 & 0.078 & -0.119 & -1.902 & 0.058 & 0.262 & -0.079 \\
\hline MD & 0.600 & 0.078 & 0.482 & 7.712 & 0.000 & 0.388 & 0.306 \\
\hline
\end{tabular}

$R=0.395, R^{2}=0.156, F_{(2,574)}=53.125, p=0.000$

Dependent Variable: EP: External pressure; Predictors: MD: Managerial decision aids, OS: Organizational support.

There is a significant relationship between "external pressure" and all of the independent variables together as can be seen in Table $10\left(\mathrm{R}=0.395, \mathrm{R}^{2}=0.156, \mathrm{~F}_{(2,574)}=53.125, \mathrm{p}<0.01\right)$. All of the independent variables together explain 15 percent of change in the total variance of external pressure.

According to standardized regression coefficients, order of relative importance of predictor variables on external pressure is managerial decisions aids and organizational support. When the t-test results which show the significance of regression coefficients are examined, it seems that only managerial decision aids is the significant predictor on external pressure. Organizational support does not have a significant effect on external pressure $(\mathrm{p}>0.05)$.

When correlations are examined it seems that there is a correlation between external pressure and organizational support $(\mathrm{r}=0.262$; when other predictor is controlled $\mathrm{r}=-0.079)$ and managerial decision aids $(r=0.388$; when other predictor is controlled $r=0.306)$.

Based upon multiple regression results, the equation can be written as follows:

External pressure $=1.578+0.600$ Managerial decision aids-0.149Organizational support

Table11. Multiple Regression Results III

\begin{tabular}{|c|c|c|c|c|c|c|c|}
\hline & \multicolumn{2}{|c|}{ Unstandardized Coefficients } & Standardized Coefficients & & & \multicolumn{2}{|c|}{ Correlations } \\
\hline & $\mathrm{B}$ & Std. Error & Beta & $\mathrm{t}$ & Sig. & Zero-order & Partial \\
\hline Constant & 0.928 & 0.164 & - & 5.648 & 0.00 & - & - \\
\hline $\mathrm{OS}$ & 0.445 & 0.049 & 0.419 & 9.141 & 0.00 & 0.705 & 0.356 \\
\hline MD & 0.382 & 0.048 & 0.362 & 7.882 & 0.00 & 0.6936 & 0.313 \\
\hline
\end{tabular}

$R=0.739, R^{2}=0.546, F_{(2,574)}=345.512, p=0.000$ Dependent Variable: PUS: Perceived usefulness; Predictors: MD: Managerial decision aids, OS: Organizational support. 
There is a significant relationship between "perceived usefulness" and all of the independent variables together as can be seen in Table $11\left(\mathrm{R}=0.739, \mathrm{R}^{2}=0.546, \mathrm{~F}_{(2,574)}=345.512, \mathrm{p}<0.01\right)$. All of the independent variables together explain 54 percent of change in the total variance of perceived usefulness. According to standardized regression coefficients, order of relative importance of predictor variables on perceived usefulness is organizational support and managerial decisions aids. When the t-test results which show the significance of regression coefficients are examined, it seems that managerial decision aids and organizational support are significant predictors on perceived usefulness.

When correlations are examined it seems that there is a correlation between perceived usefulness and organizational support $(\mathrm{r}=0.705$; when other predictor is controlled $\mathrm{r}=0.356)$ and managerial decision aids ( $\mathrm{r}=0.6936$; when other predictor is controlled $\mathrm{r}=0.313$ ).

Based upon multiple regression results, the equation can be written as follows:

Perceived usefulness $=0.928+0.445$ Organizational support +0.382 Managerial decision aids

The revised final research model can be seen in Fig.1.

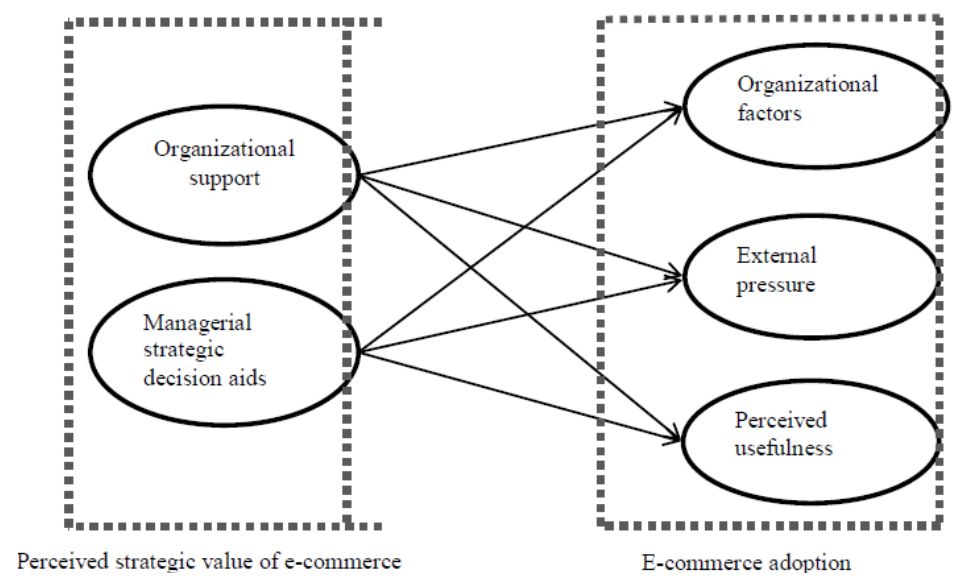

Fig1. The Revised Final Research Model

\section{Conclusion}

The purpose of this study is to explore the relationship between the perceived strategic value of ecommerce and e-commerce adoption among e-commerce adopter SMEs in Turkey. We tested reliability (Cronbach Alpha Coefficient and composite reliability) and validity (convergent and discriminant validity) concerns and found that both scales are reliable and valid. The present study showed that perceived strategic value of e-commerce consists of two dimensions such as organizational support and managerial decision aids. Moreover, e-commerce adoption has three dimensions such as organizational factors, external pressure and perceived usefulness.

Findings of the study show that to make successful strategic decisions, SMEs should take into account perceived strategic value of e-commerce and e-commerce adoption. Moreover, marketing scholars and practitioners should consider these concepts. Organizational support has a positive and significant effect on organizational factors and perceived usefulness. Managerial decision aids has a positive and significant effect on external pressure, perceived usefulness and organizational factors.

Limitation of the current study is that we have only considered adopters of e-commerce among SMEs. Non-adopters can have different perceptions on strategic value of information technologies and ecommerce adoption. Furthermore, future studies can explore larger businesses other than SMEs. Another limitation of the current study is that we used Grandon and Pearson (2004)'s e-commerce definition which is given in the introduction part of our study. As a reason of different countries have different definitions on SMEs, our SME definition is specific to Turkey. Further research should consider influencing factors such as e-marketing applications as a form of e-commerce. Scholars can compare these factors among emerging markets such as BRIC countries.

\section{REFERENCES}

[1] SME Strategy and Action Plan (2015-2018). http://www.resmigazete.gov.tr/eskiler/2015/09/ 20150905-8-1.pdf

[2] Grandon, E. E., Pearson, J. M. (2004). Electronic commerce adoption: an empirical study of small and medium US businesses, Information and Management, 42, 197-216. 
[3] Nasco, S.A., Toledo, G.E., Mykytyn Jr., P.P. (2008). Predicting electronic commerce adoption in Chilean SMEs, Journal of Business Research, 61, 697-705.

[4] Pavlou, P.A., Fygenson, M. (2006). Understanding the predicting electronic commerce adoption: an extension of the theory of Planned Behaviour, MIS Quarterly, 30(1), 115-143.

[5] Ajzen, I. (1991). The Theory of Planned Behaviour, Organizational Behavior and Human Decision Processes, 50(2), 179-211

[6] El-Gohary, H. (2012). Factors affecting E-marketing adoption and implementation in tourism firms: An empirical investigation of Egyptian small tourism, Tourism Management, 33, 12561269.

[7] Ramanathan, R., Ramanathan, U., Hsiao, H. (2012). Int. J. Production Economics, 140, 934-943.

[8] Subramanian, G.H., Nosek, J.T. (2001). An empirical study of the measurement and instrument validation of perceived strategy value of information systems. Journal of Computer Information Systems, 64-69.

[9] Kwun, O., Alijani, G.S., Omar, A., Gentry, D. (2009). Factors that Influence Strategic Value in E-Commerce Among Small Business, Southwest Decision Sciences Annual Meeting, 60-69.

[10] Chong, S., Bauer, C. (2000). A model of factor influences on electronic commerce adoption and diffusion in small-medium sized enterprises, PACIS 2000 Proceedings, 290-301.

[11] MacGregor, R., Vrazalic, L. (2008). A profile of Australian regional SME non-adopters of Ecommerce, Small Enterprise Research, 16(1), 27-46.

[12] Alam, S.S., Ali, Md.Y., Jani,M.F.M. (2011). An empirical study of factors affecting electronic commerce adoption among SMEs in Malaysia, Journal of Business Economics and Management,12(2), 375-399.

[13] Zaied, A.N.H. (2012). Barriers to E-commerce Adoption in Egyptian SMEs, I.J. Information Engineering and Electronic Business, 3, 9-18.

[14] Lim, S.C., Tan, C.P., Baharudin, A.S. (2013). Consumers' perspective view: a preliminary study on factors influence small and medium enterprises (SMEs) in Penang reluctant to adopt electronic commerce (e-commerce) application, International Journal of Accounting, Business and Management, 1(2), 1-7.

[15] Mcgorry, S. Y. (2000). Measurement in a Cross-Cultural Environment: Survey translation issues. Qualitative Market Research, 3 (2), 74-81.

[16] Hair, JF., Anderson, Re., Tatham, Rl., Black, Wc. (1998). Multivariate data analysis. 5th ed. Upper Saddle River, NJ. Prentice-Hall.

[17] Marsh, H. W., Hocevar, D. (1985). An application of confirmatory factor analyses to the study of self-concept: First and higher order factor models and their invariance across groups, Psychological Bulletin, 97, 562-582.

[18] MacCallum, R. C., Widaman, K. F., Preacher, K. J., Hong, S. (2001). Sample Size in Factor Analysis: The Role of Model Error, Multivariate Behavioral Research, 36:4, 611-637.

[19] Byrne, B. M. (2010). Structural Equation Modeling with AMOS Basic Concepts Application and Programming (Second Edition), Routledge Taylor and Francis Group.

[20] Bollen, K. A. (1989). A new incremental fit index for general structural equation models, Sociological Methods and Research, 17, 303-316.

[21] Bentler, P. M. (1992). On the fit of models to covariances and methodology to the Bulletin, Psychological Bulletin, 112, 400-404.

[22] Engel, K. S., Moosbrugger, H., Müller, H. (2003). Evaluating the Fit of Structural Equation Models: Tests of Significance and Descriptive Goodness-of-Fit Measures, Methods of Psychological Research, 8(2), 23-74.

[23] Nunnally, J. C., Bernstein, I. H. (1994). Psychometric Theory, 3rd ed., New York, McGraw-Hill.

[24] Bagozzi, R. P., Yi, Y. (1988). On the evaluation of structural equation models, Journal of the Academy of Marketing Science, 16(1), 74-94.

[25] Fornel, C., Larcker D. F. (1981). Evaluating structural equation models with unobservable variables and measurement error, Journal of Marketing Research, 18(1), 39-50. 